\title{
INVESTIGATION OF THE MOST RELIABLE LANGUAGE LEARN- ING TOOL: A STUDY ABOUT THE NEED AND IMPORTANCE OF DICTIONARIES FOR A LANGUAGE LEARNER
}

\author{
Samiya Taskeen ${ }^{1}$ \\ Muhammad Asad Habib \\ Irfan Shehzad Tarar \\ University of Lahore, Pakistan \\ Lahore Leads University \\ University of Lahore, Pakistan
}

Received: 06.07.2015

Accepted: 12.09.2015

\author{
Original scientific paper
}

UDC:81(038)

\begin{abstract}
Language learners always require some supportive tool that may assist them in their quest of learning a second or foreign language because its not an easy task to have grip over language which the learners are unfamiliar with. Traditionally the tool which had been attracted language learners is dictionary because it provides phonetic, phonological, semantic and syntactic information which paves the way of quick learning. The present article investigates the functions provided by the dictionaries regarding all aspects of language learning.
\end{abstract}

Keywords: Language preservation, learner, Pakistan, Dictionaries, pace of learning, investigation

\section{INTRODUCTION}

In Pakistani context no one can deny the need and importance of dictionaries because being non-natives of English it's always difficult for an average Pakistani student to learn a second language or get command over it without using a dictionary.

Dictionaries contain important information about various forms of a word with its meaning using sign, symbols and flowcharts, syllables of a word, history and etymology of words, how a word is hyphenated or spelled, how a word is pronounced all these things are clearly mentioned in dictionaries and this information is essential for a language learner. Marckwardt (1973) believed that the information about language which is not found elsewhere is supplied by the dictionaries. This information contains not only pronunciation, spelling or meaning rather it also includes usage, grammar and synonym of a word (Songhao, 1997).
Role of dictionaries in language learning can't be ignored. Many teachers however encourage learners to guess meaning from the context instead of wasting time in using dictionaries and such group of people believe that dictionary use should be the last resort (Knight, 1994) while one thing is obvious that in majority of the cases confirmation of guesses also requires dictionary help because guesses are not always accurate (Eslami and Huang, 2013).

\section{Language preservation through dictionaries}

Language plays a vital role in imparting culture. Languages are preserved through dictionaries. Lexicographer or linguists have been compiling dictionaries with the intentions to revive language and also to maintain it.

\footnotetext{
${ }^{1}$ Correspodence to:

Samiya Taskeen, Lecturer English at University of Education Lahore,Pakistan

Muhammad Ahmad Qadri old kahna Lahore, Pakistan.

Phone:+923116900066

E-mail: sumayataskeen@yahoo.com
} 
Dictionaries serve as a shell even for endangered languages. Hence, it's believed that dictionaries which are compiled for endangered languages serve a great purpose which is to preserve language for the upcoming generations and for revival and future studies also (Corris, Manning, Poetsch and Simpson, 2000).

\section{Dictionary versus guessing strategy}

Learners at every stage want to know the actual meanings of the unfamiliar words with the intentions to improve vocabulary and also want to understand the text according to the actual meanings of the words. It is being said that In late 70s and 80 s there appeard various substitutes odf dictionaries on the basis of which learns were advised to use dictionaries as last resort (Carnell, Devine and Eskey 1998). Teachers were supposed to train their students in guessing rather than using dictionaries. Even good language learner were considered accurate guesser by Rubin (1975) but Lufer (Laufer, 2005) argued that vocabulary learning from the text was possible only if the learns had almost $95 \%$ to $98 \%$ understanding of the text which meant according to him a learner should know 3000 to 3500 words in order to be an accurate guesser while the knowledge about language of the beginners is always limited, so guessing strategy could not produce positive outcome in majority of the cases(Gema and Angela, 2013). Guessing strategy can be appreciated but it requires contextual information. If con- textual information is not properly provided in that case brilliant guesser might suffer while contrary to this Dictionary users are free from such boundaries because they can look up from dictionary the meanings of unfamiliar words even when they are unfamiliar with context. In routine conversation sometimes speaker do use certain words which cannot be predicted even with the help of contextual information and even guesser are in certain cases bound to look them up from dictionary to understand what the conversation was about. Hence learners are in need of dictionary to confirm their guesses and also to remove their confusion about unfamiliar words (Gema and Angela, 2013).

On the basis of which this would not be wrong to say that dictionary usage was found better than guessing strategy by a number of researchers.

Hunt (2009) has found dictionary use valuable especially for the language learners.

Peters (2007) conducted a study where experiment was conducted actually on the computer. With the help of a computer scientist a java application was written with the intentions to keep the log files of the look-ups of the students. Text was directly taken from Die Zeit which was a German based newspaper. An online dictionary was also developed and students could look up the unknown words from that dictionary simply by clicking the mouse. Clicking would open a pop-up window where Dutch and German translation of the unfamiliar word would appear.

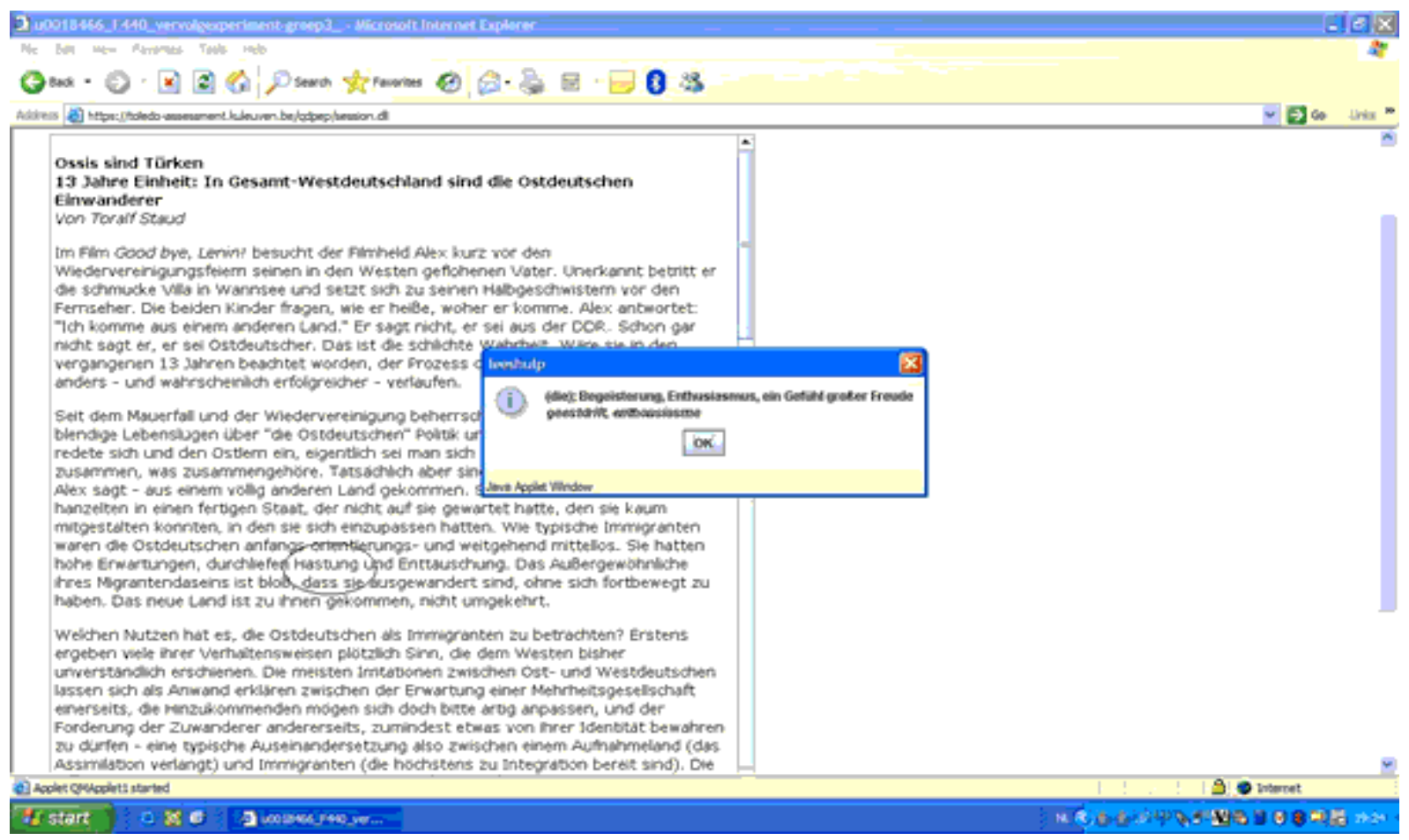

Figure 1. Pop-up and screen shoot of computer window 
There were sixteen words which were splitted up. However this was found difficult by the students to infer the meanings of all the 16 words from the context which were replaced by the pseudo words and if learners really wanted to know the meanings of those target words then the re was only one option to look them up from the dictionary.

\section{Some types of dictionaries}

Laufer and Hill (2000) believe that retention and learning can be assisted by the words. Opportunities of acquiring new words are increased with more look ups (Hunt, 2009). According to Gu and Johnson (1996), Hulstijin (1993), Zhang (2001), when learners encounter new and unfamiliar words the meaning of which they can't easily infer from the context, they just ignore the words or consult a dictionary. Most of the time they are found to consult dictionary (Prichard, 2008).

There are many kinds of dictionaries which are easily available in the market. Learners can utilize them according to their needs. Following are most widely used types of dictionaries:

\section{Bilingual Dictionaries}

Most popular dictionaries among language learners are bilingual dictionaries. The type of dictionary learns encounter first in their quest of learning is very often bilingual (Takahashi). According to Nation (2001) a survey was conducted about learners performance and results of the survey revealed that most of the learners use bilingual dictionaries. According to Baxter (1980) and Nakao (1998) Majority of college students in Japanese context use bilingual dictionaries (Loucky, 2010). Learners of almost every age and all proficiency level can utilize them to enhance their vocabulary. Such kind of dictionaries are popular at various stages of learning a language and they are helpful for vocabulary learning and reading comprehension (Atkins and Varantola, 1998; Baxter, 1980). Knight (1994) found improvement in low proficiency learners, $s$ comprehension with the help of bilingual dictionaries.

According to Hulstijn, Hollander and Grenadius (1996) and Knight (1994) Learners of low proficiency were found to use bilingual dictionaries to get the meaning of unfamiliar words and even highly proficient learners were found to use bilin- gual dictionaries by (Atkins and Varantola, 1997; Hulstijn, 1993; Knight, 1994).

An effective step in the development of the word knowledge is word-to-word translation which can easily be done with the help of bilingual dictionaries (Hunt, 2009). Roohani and Khosravi (2011) conducted a study on bilingual dictionary usage for writing support and they found positive outcome as there was significant difference between the scores of bilingual dictionary users. Well they supported the bilingual dictionary usage.

Martin (2002) has found bilingual dictionary use beneficial. He conducted a study on twenty native Chinese learners. They were divided into two groups and there task was to deal with transitive and intransitive verbs in writing. Well results of the study showed that $85 \%$ of the participants were found using bilingual dictionaries (Roohani and Khosravi, 2011).

\section{Monolingual Dictionaries}

Roohani \& Khosravi (2011) in their studies had found more improvement in the performance of monolingual dictionary users. Haag und Herchen (2001) had written in their book entitled "dictionaries and language learners" that first monolingual dictionaries were created in the first century that was almost some nine hundred years after the production of Illiad and Oddessy. Monolingual dictionaries are used by majority of the learners with the intentions to learn more about the language.

\section{Electronic dictionaries (EDs)}

Another form of dictionaries which is appreciated by learners and teachers is electronic dictionaries which are also available in the form of pocket electronic dictionaries (PEDs). Such type of dictionaries is highly appreciated because according to Tang (1997) they are fast and portable and it's quite easy to use them and they provide audible pronunciation of words which makes it quite easy for a learner to comprehend the word quickly (Hunt, 2009).

To select a word in any entry and to go directly to another dictionary namely superjump option, history, visual images, and archiving feature are available which store previously viewed words and most interesting is searching an unfamiliar word without knowing the exact meaning of the word are the dominant features of PEDs (Hunt, 2009). 
According to Abraham (2008); Boers, Eyckmans and Stengers (2004) text glosses in electronic dictionaries which are actually computer mediated are quite helpful in the comprehension of second language as they provide a lexical support to the learner. According to Al-Seghayer (2001) retention and vocabulary acquisition is quick with the help of modalities, different sounds, videos and graphics (Loucky, 2010).

\section{What is language learning?}

Language learning is a broader term which can't defined in limited words. However Oxford dictionary defines language learning as:

"The knowledge of a language which is gained through experiences, study or being taught"

Every language is comprised of some basic skills the knowledge of which is mandatory. There is a need to know about the elements or components language comprised of. Learners listen to others and speak and they read and write in order to communicate and to negotiate understanding and the new meanings. Generally these are four basic skills or pillars of a language which are to be learnt in order to learn the language fully. These are receptive and perceptive skills which are: Reading, Writing, Listening and Speaking. A learner is always in need to learn these four basic foundations or pillars of the target language. A good speaker requires exposure to listening because listening gives fluency in speech. For writing something it is mandatory that writer should be able to read. In order to get grip over these skills learners are found of using dictionaries because it's the only tool which is most supportive and authentic one for learners in helping them regarding language.

\section{Role of dictionary in learning writing skill}

One of the important pillars of a language is writing which is to be learnt while learning a language because it's a communicative skill which allows a learner to interact and negotiate. Zamel (1987) stated that writing is non linear, recursive and complex in nature and it's quite a difficult task to produce a cohesive and coherent piece of writing without learning about how to write it. With regard to the writing skill Raimes (1990) has found two different thinking lines namely product oriented views and process oriented views. Writing as product emphasizes the cohesive devices, vocabulary, grammar and spellings while on the other hand the advocates of writing as process emphasize the happenings which occurs when writer is in the process of writing; the process which actually leads the writer towards the coherent sequence of the writings. No doubt above mentioned issues have been obviously fueled by the dictionaries.

Dictionaries whether monolingual or bilingual as a tool should be in use of learners for writing tasks of the second language learning. East (2008); Hartman (1990); Horsfall (1997); Thompson, (1987) have all supported the use of dictionaries especially in writing because writing is related to language performance of learners. Henry (1996) argued that many studies by native speakers focused on the error correction of the word or sentence level. So this can be said that an authentic tool in the process of writing is dictionary. Engber (1995) also conducted a study on intermediate level learners to check the effect of bilingual dictionaries on the quality of writing. Lexical accuracy and richness which are the components of writing were measured. Results of the study indicated that bilingual dictionary usage has significant effect on writings. Its use was found positive.

Hurman and Tall (1998) conducted a study on 1300 participants. They administered two tests of writing in the French. It was quantitative work. One group of participants was instructed to complete the task with the help of dictionaries while other did it without the help of the dictionaries. Results of the study highlighted that the scores of dictionary users were greater as compare to the other group (Roohani and Khosravi, 2011).

\section{Role of Dictionaries in learning Reading skill}

Reading is essential when language learning is target. Dictionary usage is helpful in improving reading. Reading performance of second language is influenced by dictionary usage according to Hayati (2005). He conducted a study on 45 intermediate students who were learning a second language. Hayati divided the participants into three groups: monolingual group which was supposed to use monolingual dictionaries, group two was bilingual group which used bilingual dictionaries and group three was controlled group participants of which were not allowed to use dictionaries rather they were asked to utilize contextual guessing. A reading comprehension test was administered. Results of the study supported the bilingual dictionary usage because bilingual group got the highest scores as compare to other two groups (Roohani and Khosravi 2011). 
Learners use dictionaries while reading when they encounter unfamiliar words. Hosenfeld (1977) and Adamson (1990) observed in their studies that all the participants use dictionaries while reading however less successful participants were found to use them more than those participants who were more successful. Paribakht and Wesche (1993) in their study of second language learning strategies had seen the dictionary used by all the university students which was a strategy for them of language learning. Consulting a dictionary while reading is a strategy of second language learners and they utilize this consultation. According to Bensoussan, Sim, and Weiss (1984) dictionary usage is beneficial when used while reading. Luppescu and Day (1993) conducted a study to determine the benefits of dictionary usage in understanding the reading tasks and vocabulary enhancement. As it was an experimental study. So participants were dived into two groups. Results showed that with dictionary group achieved 50\% higher scores as compare to non dictionary group which proved that bilingual dictionary usage was beneficial to enhance vocabulary through the reading. Knight (1994) conducted a study on the students of different verbal ability and concluded with a supportive attitude towards dictionary usage which was found helpful in enhancing reading comprehension (Fraser, 1997).

\section{Role of dictionaries in learning listening skill}

Listening is a very important skill which helps is improving speaking. A good listener can easily be a good speaker. Without listening it would not be possible to speak well. Electronic dictionaries are quite helpful in this regard. Native language explanations and equivalents are available in most of them. Definitions of the words and example sentences with explanation which are given in native language are also the features of such electronic dictionaries. Their role in improving listening is found quite helpful as they have the quality to speak and by listening it again and again the learners can improve their listening.

\section{Role of dictionaries in learning speaking skill}

Language learning is incomplete without learning how to speak. Speaking is an important skill which is mandatory in order to communicate. Halliday (1980) believes that our thinking and understanding are enhanced through speaking. In every day life learners listen to others and in order to respond they are in need to speak. Speaking helps people to reflect their thinking, ideas and information they have in their minds (PYP, 2009).

In earlier time dictionaries were tools which were designed to fulfill the needs of audience i.e. to help them in their communication with the people of different languages. Dictionaries which were designed first of all were bilingual. In these dictionaries Sumerian words were registered along with their Eblaite translations and the aim behind developing such dictionaries was to develop communication skills (Haag und Herchen, 2001). There are now a days online dictionaries which are easily accessible which are providing speaking support to learners. Talking dictionaries can guide towards correctness pronunciation.

\section{About structure of a language}

Structure of a language is neither easy rather it's always complicated which is to be studied deeply if intentions are to learn a language. Every language has governed some rules. Almost all the languages of the world have some components which help in easy understanding of the language. Let's have a look on them.

\section{Components of Language}

Following serve as the components of the language: Sound system known as phonological component Phonological components of a language are concerned with sounds. It studies how sounds are organized to make meaningful expressions. Production of speech sounds and sound patterns within a language are all studied by phonological component. Diachronic and synchronic study of sounds, production, perception and reception of sounds, history and etymology of sounds, sound changes, pronunciation etc all are connected to phonological component of the language and a learner is in need to learn it if he aims to learn listening skill.

\section{Morphology}

It is known as the grammar of words. The morphemes of a language are studied and analyzed under the scopeof morphology.

\section{Syntax}

Syntax is concerned with the arrangement of words in a sentence. Chomsky,s theories about the sentence structures are really helpful in this regard. 
A learner should learn how to arrange words in order to make proper sentences otherwise he or she would not be able to convey what he or she actually intends to. All the languages have got some specific rules which are known as the grammar of that language which helps in learning about how to connect words in a way that a meaningful sentence can be produced. With the help of grammar of the language learner would be able to produce infinite number of sentences and even it would be possible to produce such sentences which never heard before by the speaker. A speaker can produce an infinite number of sentences with the help of finite number of rules of that specific language.

\section{Semantics}

Studying meaning is also an important component which gives knowledge about language. Acquiring correct meaning of the words has been an important concern. How linguistic elements carry the meanings is generally known as semantics. All the Languages of the word contain thousands of words or vocabulary items which refer to ideas or concepts. So it seems as if words are the sources through which languages convey meanings. This is the reason that at early stage

\section{Theories of language learning}

Malone (2012) has summarized the second language learning theories and methods in the following way:

Pre-20th Century Grammar translation Method

Early 1900s

1940s, 1950s

Audio-lingual, Direct method

$1960 \mathrm{~s}, 1970 \mathrm{~s}$

Behaviorists

1980s, 1990s

1940s, Present

Universal Grammar, LAD

information processing models

Social interactionism

Learning a language is not easy rather it is a time taking and complicated process which requires proper attention. Researchers had given various theories about learning process. A well known and renowned Stephen krashen has worked on the process of learning and presented a model which explains with the help of five hypotheses in detail how a learner proceeds towards second language learning. Hypotheses are:

\section{The Acquisition-Learning hypothesis}

According to the acquisition-Learning hypothesis there are two ways of developing competence in adults which are acquisition and learning where acquisition is concerned with the language usage in of learning learners does learn meanings of the words first. No doubt semantic has got a complex structure but its understanding helps the learner to comprehend intended meanings and context based discourse.

\section{Pragmatics}

Understanding about the intended meaning of a speaker is an important thing. It is not possible all the time to get the lexical meaning of spoken or written discourse rather understanding about the intentions behind saying should be developed. Intended meanings are studied under the scope of pragmatics. Learners' may be able to read, write and may also be able to spell the words correctly in isolation but this is also a fact that learners most of the time are not able to do the same in some different context that is the place where pragmatics plays its role (PYP, 2009). Use of certain dialogues in different situations according to the contexts for communicating purpose is taught by pragmatics (Ninio and Snow, 1999). In order to avoid misunderstandings in accurate understanding and interpretation of communications the knowledge of pragmatic elements is necessary for a language learner (Deda, 2013).

\author{
Bloomfield, Fries \\ Skinner \\ Chomsky, Krashen \\ Anderson, McLaughlin \\ Vygotsky, Snow
}

communication and learning is concerned with the knowledge about language.

\section{The Monitor hypothesis}

It is concerned with conscious learning.

\section{The Input hypothesis}

There is only one way to acquire language by humans and that is by receiving input.

\section{The Natural Order hypothesis}

According to this acquisition- learning hypothesis the rules of a language are acquired in a predictable order. The Affective Filter hypothesis:

It's a mental block. 


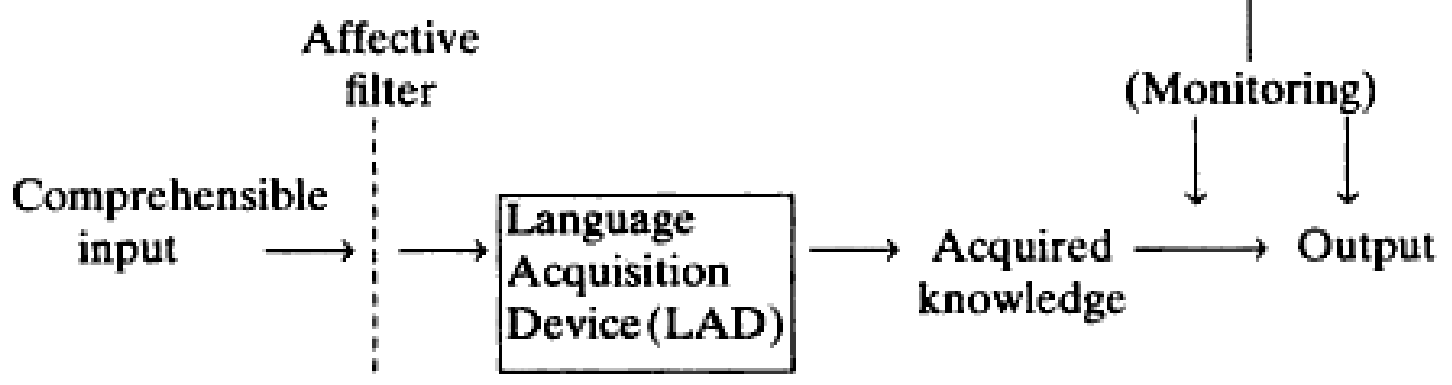

\section{Learnt knowledge}

The Input Hypothesis Model of L2 learning and production (adapted from Krashen, 1982, pp. 16 and 32; and Gregg, 1984)

\section{Behaviorism Approach}

Another approach towards learning is behaviorism. The components of this approach argued that learner learn through repetition and imitation. Re-enforcement plays a vital role here. This school believes that behaviors are measurable and can be explained. Stimulus-response is the basic of behaviorism theory. Behaviorist school of thought was started by Watson; B. F Skinner is one of the major components of this.

\section{Bloom's Taxonomy}

Leaning brings change as Borger and Seaborne (1966) believed that permanent change in behavior is learning. Educationists and researchers had given countless theories regarding learning in which Bloom's Taxonomy has got a dominant place who has divided learning outcomes into three domains:
Cognitive domain (Thinking and understanding)

Affective domain (emotion and feelings)

Psychomotor domain (ability to manipulate physical tools) (Surgenor, 2012)

Which are further divided into sub-categories. This Taxonomy was created by Benjamin Bloom in 1956. It was created by Dr Bloom for academic Education but it is related to all types of learning Figure is giving an explicit explanation of the taxonomy. Blooms basic focus was on cognitive domain which was published under the title: Taxonomy Of Educational Objectives: Handbook 1, The Cognitive Domain' (Bloom, Engelhart, Furst, Hill and Krathwohl, 1956). In 1964 second book appeard which focused on the affective domain. Title of this version was : Handbook II, The Affective Domain' (Bloom, Masia, Krathwohl). Krathwhol was the one who divided affective domain into sub categories.

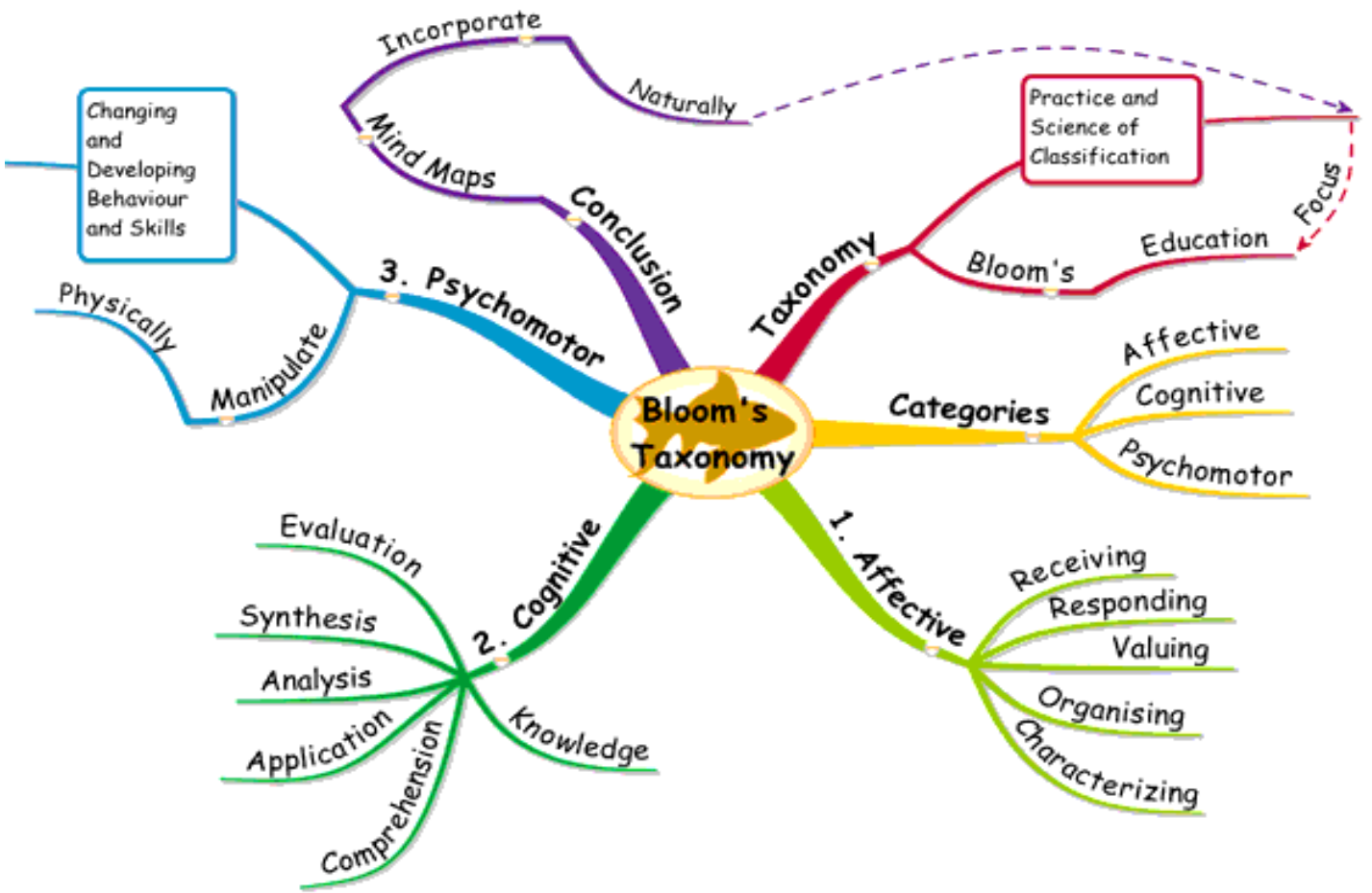

Source:http://www.mindmaptutor.com/2010/04/mind-mapping-and-blooms-taxonomy/

Figure 2. Sub categories of bloom's Taxonom 


\section{REFERENCES}

Corris, M., Manning, C., Poetsch, S., \& Simpson, J. (1999). Dictionaries and endangered languages, University of Sydney and Stanford University Endangered Languages Workshop La Trobe University, 30 November 1999

Deda, N. (2013). The role of Pragmatics in English Language Teaching. Pragmatic Competence: Academic Journal of Interdisciplinary Studies Published by MCSER-CEMAS-Sapienza University of Rome

Eslami, Z. \& Huang, S. (2013). The Use of Dictionary and Contextual Guessing Strategies for Vocabulary Learning by Advanced English-Language Learners, De Lin Institute of Technology, Taiwan English Language and Literature Studies; Vol. 3, No. 3; Published by Canadian Center of Science and Education

Fraser, (1997). The Role of Consulting a Dictionary in Reading and Vocabulary Learning York University. http://yorkspace.library.yorku.ca/xmlui/bitstream/handle/10315/1331/ CRLC00147.pdf?sequence $=1$

Gema, A., \& Angela, A. (2013). The Bilingual Dictionary and Foreign Language Learning, Facts and Opinions, Porta Linguarum 20, pp. 89-101

Gu, Y. P. (2013). Vocabulary Learning in a Second Language: Person, Task, Context and Strategies: The Electronic Journal for English as a Second Language 7(2).

Humblé, P. (2001). Dictionaries and language learners for www. pget.ufsc.br

Herrnstein, R. J. (1977). The evolution of behaviorism. American Psychologist, 32., pp. 593-603. doi: 10.1037/0003066X.32.8.593

Hayati, M. \& Fattahzadeh, A. (2006). Effects of bilingual and monolingual dictionaries on vocabulary recall and retention of Efl learners: The reading matrix 6(2). pp 125-134.

Jin, L. \& Deifell, E. (2013). Foreign Language Learners' Use and Perception of Online Dictionaries: A Survey Study. MER-
LOT Journal of Online Learning and Teaching 9(4).

Knight, S. (1994). Dictionary use while reading: The effects on comprehension and vocabulary acquisition: elt English Language Teaching Vol. 6, No. 6; 201385

Loucky, J. P. (2010). Comparing Electronic Dictionary Functions and Use. CALICO Journal, 28(1).

Malone, S. (2012). Theories and research of second language acquisition: SIL international Benkok

Ninio, A. \& Snow, C. (1999). The development of pragmatics: Learning to use language appropriately. Invited chapter, in T. K. Bhatia \& W. C. Ritchie (Eds.), Handbook of language acquisition (pp. 347-383). New York: Academic Press.

Peters, E. (2007). Manipulating L2 Learners' Online Dictionary Use And Its Effect On L2 Word Retention : Language Learning \& Technology 11(2), pp. 36-58

Prichard, C. (2008). Evaluating L2 readers'vocabulary strategies and dictionary use. Ferris Women's University Japan

Primary Years Programme. (2009). Language scope and sequence, International Baccalaureate Organization 2009: PYP 10 Printed in the United Kingdom by Antony Rowe Ltd, Chippenham, Wiltshire 7.

Roohani, A. \& Khosravi, A. (2011). An Investigation into Bilingual Dictionary Use: Do the Frequency of Use and Type of Dictionary Make a Difference in L2 Writing Performance? The Journal of Teaching Language Skills (JTLS) 3(2), Ser. 63/4 (Previously Journal of Social Sciences \& Humanities)

Songhao, L. (1997). Dictionary use as a way of learning vocabulary in sla: a preliminary study on Three Chinese Learners of English as a Second Language at the University of the South Pacific Students of different verbal ability. The Modern Language Journal, 78(3), pp. 285-299. http://dx.doi. org/10.1111/j.1540-4781.1994.tb02043.x

Watson, J. B. (1928). The ways of behaviorism: Oxford, England: Harper. 144 pp.

You, Y. (2011). Factors in Vocabulary Acquisition through Reading, INTESOL Journal, 8(1). 